\title{
Social Competence and Moderate to Vigorous Physical Activity of School-Aged Children through a Creative Physical Education Intervention
}

\author{
Arto Gråstén ${ }^{1 *}$, Marja Kokkonen², John Quay³, Juha Kokkonen" ${ }^{4}$ \\ ${ }^{1}$ School of Education, University of Tasmania, Launceston, Australia \\ ${ }^{2}$ Faculty of Sport and Health Sciences, University of Jyväskylä, Jyväskylä, Finland \\ ${ }^{3}$ Melbourne Graduate School of Education, University of Melbourne, Melbourne, Australia \\ ${ }^{4}$ Department of Teacher Education, University of Jyväskylä, Jyväskylä, Finland \\ Email: *arto.grasten@utas.edu.au, marja.kokkonen@jyu.fi, jquay@unimelb.edu.au, juha.a.kokkonen@jyu.fi
}

How to cite this paper: Gråstén, A., Kokkonen, M., Quay, J., \& Kokkonen, J. (2019). Social Competence and Moderate to Vigorous Physical Activity of School-Aged Children through a Creative Physical Education Intervention. Advances in Physical Education, 9, 129-144.

https://doi.org/10.4236/ape.2019.92010

Received: April 4, 2019

Accepted: May 7, 2019

Published: May 10, 2019

Copyright $\odot 2019$ by author(s) and Scientific Research Publishing Inc. This work is licensed under the Creative Commons Attribution International License (CC BY 4.0).

http://creativecommons.org/licenses/by/4.0/

(c) (i) Open Access

\begin{abstract}
Traditional school physical education focuses on physical skills or strategies with an expectation that learning these skills lead to healthier lifestyle outside physical education classes, while children's overall moderate to vigorous physical activity (MVPA) is widely decreasing. Creative Physical Education (CPE) understands physical education more holistically, as the central pedagogical element of movement is social learning. The current study examined the development of social competence in school physical education (PE) and total moderate to vigorous physical activity (MVPA) participation through a CPE-based intervention. Participants were 363 (177 intervention, 186 control) children from public elementary schools in Central Finland. The data collection was completed across two measurement points using questionnaires. The key findings were that: 1) the associations between social competence and MVPA engagement were relatively weak and 2) the 12-month intervention was effective in increasing students' social competence in PE and total MVPA engagement. CPE teaching practices could provide positive social experiences in PE. However, applying new strategies into actual school settings may take time, and therefore, children need to be given sufficient timeframe to take ownership of the activities.
\end{abstract}

\section{Keywords}

Development, Student-Centered, Pedagogy, Longitudinal, Multi-Level Model 


\section{Introduction}

Many children are not doing enough moderate to vigorous physical activity (MVPA) to maintain good health and well-being (Tremblay et al., 2016). According to the World Health Organization (2018), MVPA requires a moderate amount of effort and noticeably accelerates the heart rate, for instance via brisk walking, running, jumping, or playing ball games. Schooling is arguably one of the most cost-effective avenues for increasing children's daily MVPA engagement (McKenzie, 2007), with physical education (PE) being a core curriculum area that can contribute to this aim. Traditionally, PE has focused on the skill elements of physical activities or sports, with an expectation that learning these skills leads to healthier lifestyle choices outside the PE classes (Kulinna, 2008). In addition, PE teachers have adopted teacher-directed teaching methods, an occurrence prevalent in Finland (Jaakkola \& Watt, 2011). However, these aspects of traditional PE (Kirk, 2013; Kulinna, 2008), have coincided with a decrease in overall MVPA levels in many countries (Tremblay et al., 2016). Another concurrent occurrence is the inclusion, in the Finnish National Curriculum for Basic Education, of social and emotional learning objectives; for instance, the appreciation of others, tolerance, being responsible and considerate, cooperation, and emotional expression (Finnish National Board of Education, 2004). These developments indicate the need for a shift in focus for PE, along with more student-centered teaching strategies (Gråstén \& Yli-Piipari, 2019; Ntoumanis \& Standage, 2009; Slingerland, 2014). A pedagogical model offering such an alternative is Creative Physical Education (CPE), which positions the sociality of the physical experiences as central to engagement with movement (Quay \& Peters, 2012; Quay, Kokkonen, \& Kokkonen, 2016). This study aimed to investigate associations between social competence in PE and total MVPA engagement through a CPE-based intervention.

\subsection{The Creative Physical Education Model}

CPE reverses the traditional emphasis on skill development, which positions social learning as a matter of classroom management (Quay \& Peters, 2012). Skill development is always important, but CPE considers this a consequence of engaged participation in meaningful social physical activity, rather than a necessary precursor. Skills develop and are used in context; CPE is an approach which highlights the pedagogical design of this context. The first layer of this context is the game in which skills are applied. The second layer is provided by the various features of sport, such as competition, festivity, seasons, within which the game sits. The third layer of context is the set of social expectations of the local community.

In CPE, students are organized in teams which emphasize the social expectations of being a team member, drawing on an adaptation of Hellison's (2010) work in taking personal and social responsibility in PE. This is important because the teams stay together for the length of the unit, which is different than traditional PE where they only exist for one class. Based on a process which emphasizes design criteria (incorporating skills and other game features) and pro- 
vision of feedback between teams (through a regular sharing process), the teams create and refine games (Quay \& Peters, 2012; Quay et al., 2016). The games are then played in a competition which emphasizes improvement at the level of the team, encouraging team investigation and planning for practice, around issues such as skill performance, game strategies, teamwork and fitness.

The differences between traditional PE (Kirk, 2013; Kulinna, 2008), and $\mathrm{CPE}$-based teaching in relation to these main elements include: 1) teams are a management tool vs. teams are central to the educational enterprise; 2) game management is a teacher's responsibility vs. game development is students' responsibility via design criteria, teaching others, giving and receiving feedback; 3) seasons are not important as the focus is the skill development vs. seasons provides for multiple performances (e.g. motor skills, team strategy, fitness, team belonging) focused on improvement; and 4) the practice is the priority but for many students is only meaningful as teacher impels participation vs. practice sessions are developed by students themselves using need-based assessment and feedback (Quay et al., 2016). Further distinctions between CPE and other pedagogical models such as Sport Education are detailed in Kokkonen, Yli-Piipari, Kokkonen and Quay (2018).

\subsection{Self-Determination Theory}

The present intervention was guided by Self-determination Theory (SDT; Deci \& Ryan, 2000; 2008), a theoretical framework supporting analysis of associations between social experiences and physical activity behavior in the school context. SDT proposes that people feel motivated by activities, which allow them to satisfy basic psychological needs, i.e. competence, autonomy, and social relatedness. Competence is defined as a perceived self-belief in one's ability to perform well in an activity, whereas autonomy represents freedom of choice. Perceived autonomy is high when individuals feel they are engaging in activities because they choose to do so, not because they feel pressured by other people or external factors. Social relatedness is defined as a sense of shared experience and meaningful relationships with others.

Applied to the PE context, if a student feels that activities allow satisfaction of these basic needs, interests toward activities are driven by intrinsic motivation. Furthermore, intrinsically motivated students are more likely to perceive their $\mathrm{PE}$ experiences as positive, leading them to be more physically active (Weiss, 2000). Several previous studies have found that competence seems to be the strongest predictor of intrinsic motivation over autonomy and relatedness in the PE context (e.g. Ferrer-Caja \& Weiss, 2000; Standage, Duda, \& Ntoumanis, 2003; Taylor, Ntoumanis, Standage, \& Spray, 2010). Considering this, past research has mainly focused on physical competence, but relatively few studies have focused on social competence ( $\mathrm{Su}, \mathrm{Wu}, \& \mathrm{Su}, 2017)$, although PE activities are typically delivered as group activities.

Social competence is the ability to achieve personal goals in social interaction while developing and maintaining positive relationships with others (Rubin \& 
Rose-Krasnor, 1992). It is widely accepted that improved social competence is associated with children's psychological and social well-being (Berndt, 2002; Su et al., 2017). Building on this line of previous SDT research and the social aspects of school PE, further studies are needed to understand social competence in a variety of contexts, especially in the physical activity domain.

\subsection{The Purpose of the Study}

The present study provides important insights into the links between social competence and MVPA engagement in the physical activity context. While previous studies have not directly measured the relationships between students' perceptions of social competence and MVPA participation (Bailey, 2006; Su et al., 2017), this study focused on these associations with an assumption that children's social competence in PE and overall MVPA could be enhanced by using student-centered methods in school PE. The impacts of CPE-model on social competence and overall MVPA engagement have not been empirically tested, although the model has received support in the PE context (Kokkonen et al., 2018; Quay, 2015; Quay et al., 2016). According to a large systematic review of Dobbins et al. (2013), most previous school-based physical activity interventions have been analyzed through the disparities between intervention and control groups, whereas multi-level models can be simultaneously examined on the individual and group level. The tests of specific effects for dependent variables are more powerful in the multi-level analysis, which are visible in the form of smaller standard errors (Snijders \& Bosker, 2012). Based on the existing evidence, the present study examined associations between social competence and MVPA engagement using a two-level model to explain perceptions of social competence and total MVPA levels through school-based intervention including student-centered teaching strategies (Figure 1).

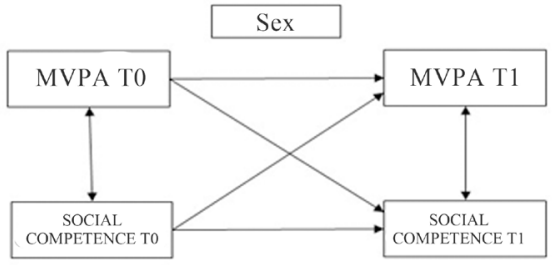

WITHIN

BETWEEN

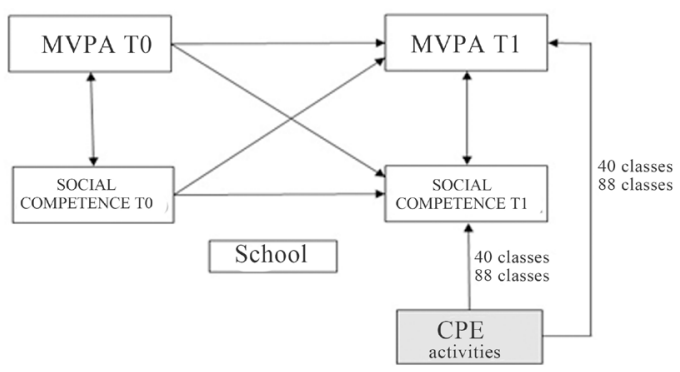

Figure 1. The theorized two-level model of social competence and MVPA engagement. 
The aims of the study were 1) to examine the associations between social competence and total MVPA levels in intervention and control students, and 2) to analyze the effects of CPE strategies on social competence and MVPA levels across the intervention. Based on the previous studies, it was expected that the higher perceptions of social competence would be linked with more frequent overall physical activity (Bailey, 2006; Su et al., 2017). Intervention students were expected to be more physically active (Metcalf, Henley, \& Wilkin, 2012; van Sluijs, McMinn, \& Griffin, 2007) and to score higher on social competence (Bailey, 2006) than control group students. Finally, girls were supposed to be less physically active than boys (Tremblay et al., 2016) but more socially competent than boys (Kwon, Kim, \& Sheridan, 2014; Merrell, Felver-Gant, \& Tom, 2011, Su et al., 2017).

\section{Methods}

\subsection{Participants}

Participants were 363 (172 girls, 191 boys) elementary school children aged between 10- to 12 -years ( $M=11.20 \pm .78$ years) recruited from two public schools in a middle size town located in Central Finland. All fourth- to sixth-grade children were invited to participate through the direct contact with the school principals. Nearly $5 \%$ of elementary school children in the region participated in the study. Written assents were also obtained from children with guardian consents. All students who returned signed forms were permitted to participate in the study. Participation was voluntary and no extra credit was awarded for the participation. Study approval was obtained from the local education authorities.

\subsection{Measures}

Social competence. Perceptions of social competence were measured using the Multisource Assessment of Children's Social Competence Scale (MASK) (Junttila, Voeten, Kaukiainen, \& Vauras, 2006). The questionnaire used in the current study had the individual item stem of "Using the scale below, circle the number that best describes you in PE classes." The scale consisted of 15 items measuring four dimensions of social competence. The dimensions were cooperation (e.g. $I$ participate effectively to group activities), empathy (e.g. I am sensitive to the feelings of others), impulsivity (e.g. I have a short fuse), and disruptiveness (e.g. I argue and quarrel with peers). Items were rated on a 4-point scale ranging from never (1) to very frequently (4). Impulsivity and disruptiveness scores were reversed, for example, a 1 would be converted to a 4 . Mean scores of cooperation, empathy, impulsivity, and disruptiveness were calculated. Final scores were scaled using the original 4-point scale and used as social competence scores. Based on the self-reports of 222 Finnish fourth-grade students, the model supported the construct validity $(N F I=.95, R M S E A=.050, S R M R=.034)$ and internal consistencies of cooperation $(\alpha=.80)$, empathy $(\alpha=.68)$, impulsivity ( $\alpha$ $=.80)$, and disruptiveness $(\alpha=.74)$ dimensions of the scale (Junttila et al., 2006). 
Self-reported MVPA. Children's MVPA engagement was assessed using the Health Behavior in School-aged Children Research Protocol (HBSC) (Currie et al., 2012). The introduction preceding the items was "In the next two questions physical activity means all activities which raises your heart rates or momentarily get you out of breath for example in doing exercise, playing with your friends, going to school, or in school physical education. Sport also includes for example jogging, intensive walking, roller skating, cycling, dancing, skating, skiing, soccer, basketball and baseball." The items required children to summarize their time spent in MVPA in the following way: "When you think about your typical week, on how many days are you physically active for a total of at least $60 \mathrm{mi}$ nutes per day?" and "Over the past 7 days, on how many days were you physically active for a total of at least 60 minutes per day?" Both items rated on an eight-point response scale (0 to 7 days). The mean score of the two items represented children's total MVPA scores. Gråstén and Watt (2016) reported that for a sample of 998 Finnish fifth- through eighth grade students, the MVPA items had reliable measurement properties $(\alpha=.91)$ and low to moderate correlations (.35 to .51) with the accelerometer scores based on a seven-day data collection.

\subsection{Procedure}

The data collection was completed across two measurement points, starting in November 2011 (T0) and continuing until March 2013 (T1). However, the follow-up data of sixth-grade children was collected in April 2012, before they transferred to the secondary school. Intervention school students responded to the online questionnaires under the supervision of the teacher in the computer lab and control school students to the equal paper-and-pencil questionnaires under the supervision of the principal investigator in the school gym. The principals and teachers preferred this schedule and data collection arrangements. Children were advised to ask help if needed and they were encouraged to answer honestly and assured that their responses were confidential. In addition, children were told that their involvement was voluntary, and they could terminate their participation at any time without consequences. Schools were not randomized, both intervention and control schools decided voluntarily to participate in the study. Children represented 22 study groups taught by eight teachers ( 5 females, 3 males) with previous teaching experience in PE.

\subsection{Intervention}

The central assumption of the intervention was that children's overall MVPA could be enhanced by using CPE-based teaching methods in school PE. The study took place in two middle-size (in total of 500 students per school) elementary schools, which followed the National Core Curriculum for Basic Education (Finnish National Board of Education, 2004). In Finland, the national curriculum includes: 1) developing basic motor skills and specific forms of physical ac- 
tivity, 2) understanding the importance of regular physical activity for health and well-being, 3) observing and developing of functional abilities, 4) developing swimming and water-rescue skills, 5) learning to act safely and appropriately in situations of physical activity, 6) learning to work independently and in a group, 7) learning to accept themselves and tolerate diversity, and 8) learning to look for information on local possibilities for exercising (Finnish National Board of Education, 2004). Based on the national curriculum, schools draw up their own curriculum considering local conditions. Basic education is publicly funded, and the education providers are responsible for teaching arrangements. The government decides upon class hours required for PE during basic education. In the current study, sixth-grade students participated in an average of 40 and fourthand fifth-grade students an average of $88 \mathrm{PE}$ classes of 45 minutes each. Intervention school classes were based on the principles of the CPE model (Quay, 2015), whereas neither teachers nor students in the control school had any training related to $\mathrm{CPE}$.

A research group possessing relevant expertise designed the content of the intervention in collaboration with intervention teachers. The developer of $\mathrm{CPE}$ model presented in a two-day seminar the theoretical principles of the model together with practical demonstrations to all intervention school teachers. Six teachers agreed to organize CPE-based intervention through their PE classes. Next, a supplemental workshop among intervention school teachers was organized to reinforce the theoretical principles of the CPE model and to apply the principles to the intervention school considering local possibilities. Furthermore, the original English CPE student workbook was translated into Finnish and educational materials were provided. The intervention was operationalized between research group-teachers and between teachers-students. In the control school, all PE classes focused primarily on achieving movement skills (i.e. running, jumping, and throwing in different forms of activities, gymnastics, gymnastics with equipment and apparatus, dance, ball games, orienteering, skiing, skating, swimming, and development of physical functional skills). Socio-ethical aims were planned to be achieved through technique-based multi-activity approach. In contrast, the intervention considered the four main elements (team, game management, season of games, and practice) of CPE model including activities such as completing workbooks, homework, and teaching games and physical activities and to other students (Table 1). A detailed description of intervention protocols and activities was recently reported elsewhere (Kokkonen et al., 2018; Quay et al., 2016).

\subsection{Data Analysis}

First, normal distribution, outliers, and missing values were examined. The data were normally distributed. However, based on the standardized values, the study variables contained 19 significant outliers out of total 363 completed questionnaires. The closer examination revealed that some children did not provide congruent responses to all items, and thus, the outliers were removed. A total of 
Table 1. The manipulation of the CPE elements.

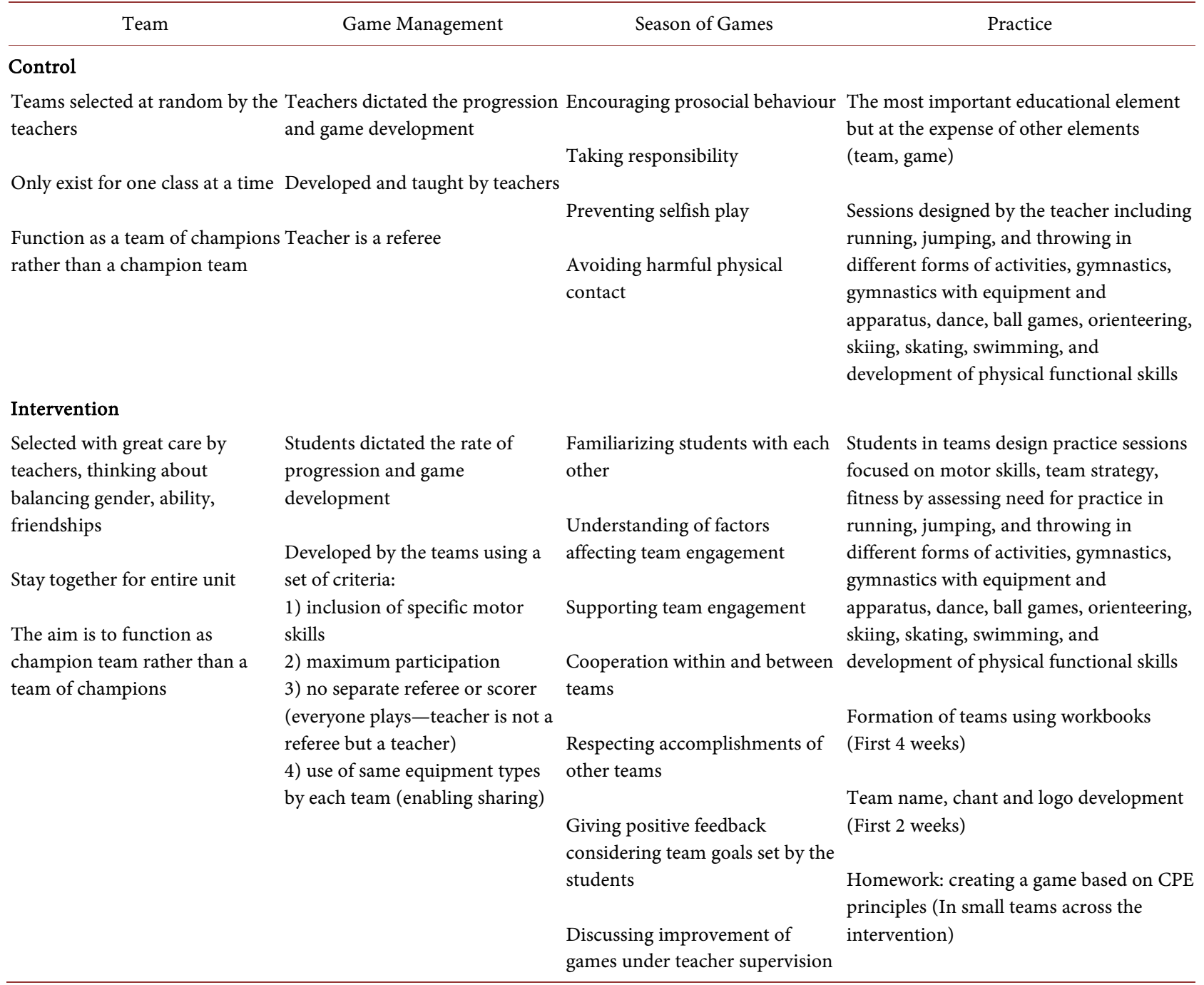

8.3\% missing values in study variables were found, as some children did not provide fully completed questionnaires. Missing completely at random (MCAR) -test $\left(\chi^{2}=119.800, d f=74, p<.001\right)$ and frequencies of sex and school indicated that the missing values were missing at random (MAR) (Little \& Rubin, 2002). Missing values were not imputed but estimated using the full information maximum likelihood, which has been shown to produce unbiased parameter estimates and standard errors under MAR conditions (Muthén \& Asparouhov, 2003).

Second, descriptive statistics including correlations, Cronbach alphas, means, and standard deviations were determined. To answer the research questions, a two-level regression model was implemented. The primary objective of two-level model was to summarize within-group variability at individual level and between-group variability at the cohort level. The current data consisted of two measurement points (T0, T1), in which the within-level examined the associations between sex and repeated social competence and MVPA measures. The 
between-level represented the relationships between schools, social competence and MVPA, and intervention activities. The effects of short- and long-term intervention on MVPA at T1 were tested using dummy coded variables. In the case of the two-level regression model, fit indices were not provided but the model fit was evaluated by comparing Akaike (AIC) and Bayesian (BIC) information criterion of the model without predicting variables with the final model (Muthén \& Muthén, 2013). The missing data analysis was performed using SPSS Version 22.0 and the two-level model using Mplus Version 8.0.

\section{Results}

\subsection{Descriptive Statistics}

First, the correlation coefficients, Cronbach alphas, means, and standard deviations of the study variables were examined (Table 2). The correlations between variables ranged from negligible to moderate. The strongest positive correlation was found between control group's MVPA scores at T0 and T1. Mean scores indicated that children's perceptions of social competence were relatively high in both intervention and control group. Additionally, children reported to be physically active on most days of the week. The Cronbach alphas of the scales were acceptable in both groups.

\subsection{Two-Level Model of Social Competence and MVPA Engagement}

To examine the associations between social competence, MVPA participation, sex, school, and intervention activities, the two-level regression model was implemented. Akaike and Bayesian's information criterion indicated that the final model $(A I C=3469.26, B I C=3609.36)$ was more strongly supported by the present data than the model without predicting variables $(A I C=5547.93, B I C=$ 5672.55), and thus, the final model was selected for the further examination (Figure 2).

At the within-level, the model revealed that the associations between social

Table 2. Correlations, Cronbach alphas, means, and standard deviations of the study variables.

\begin{tabular}{cccccccc}
\hline & 1 & 2 & 3 & 4 & $\alpha$ & $\mathrm{M}$ & $\mathrm{SD}$ \\
\hline 1 Social competence T0 & - & .16 & .06 & .04 & .79 & 3.10 & .53 \\
2 Social competence T1 & $.21^{\star}$ & - & -.04 & $.21^{* *}$ & .80 & 2.96 & .59 \\
3 MVPA T0 & -.01 & -.07 & - & $.30^{* * *}$ & .88 & 5.46 & 1.53 \\
4 MVPA T1 & .12 & .03 & $.44^{* * *}$ & - & .90 & 5.49 & 1.45 \\
$\alpha$ & .85 & .85 & .78 & .84 & & & \\
M & 3.27 & 3.23 & 5.52 & 5.50 & & & \\
SD & .64 & .62 & 1.46 & 1.33 & & & \\
\hline
\end{tabular}

Notes. Descriptive statistics for the intervention group $(\mathrm{n}=177)$ are presented above the diagonal and descriptive statistics for the control group $(\mathrm{n}=186)$ are presented below the diagonal. ${ }^{* *} p<.001,{ }^{* *} p<.01$, ${ }^{*} p<.05$. 


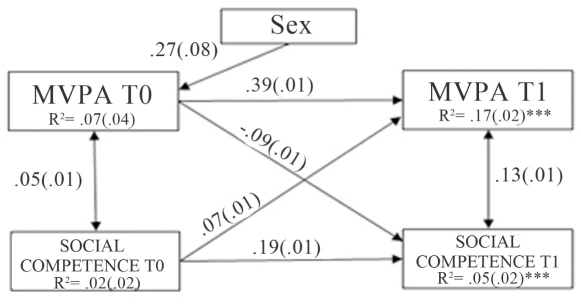

WITHIN

\section{BETWEEN}

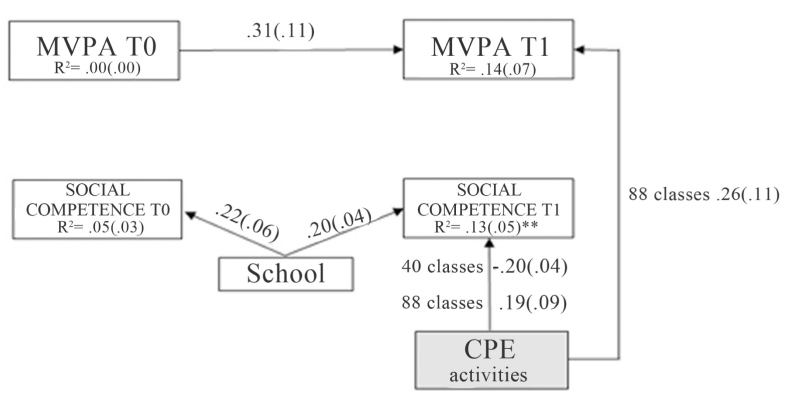

Figure 2. The standardized parameter estimates of the two-level model (standard errors in parentheses). All paths are significant at $p<.05$ level. ${ }^{\star * *} p<.001,{ }^{* *} p<.01$.

competence and MVPA engagement were negligible. Boys $(5.76 \pm 1.47)$ were more physically active than girls at T0 $(5.21 \pm 1.47)$. No significant MVPA differences between intervention and control schools were found at $\mathrm{T} 0$ and $\mathrm{T} 1$ on the between-level. The long-term intervention activities were significant predictors of MVPA at T1, whereas the short-term intervention activities were statistically insignificant. Perceptions of social competence were higher among control group students at both T0 and T1. However, the long-term intervention activities had a positive influence on social competence at T1. No significant differences in means or variances of social competence and overall MVPA between intervention and control schools, but significant variations between individuals were found at $p<.05$ level. MVPA T0 moderately associated with MVPA T1 on both levels, when social competence T0 related with social competence $\mathrm{T} 1$ on the within-level only. Finally, squared multiple correlations revealed that the model explained $17 \%$ of the variability of MVPA at T1 (at within level) and 5\% (within) and $13 \%$ (between) of social competence at $\mathrm{T} 1$.

\section{Discussion}

The aims of the study were to examine the associations between social competence and overall MVPA engagement in intervention and control students, and to analyze the effects of CPE intervention on social competence and MVPA levels across the CPE-based intervention. The key findings were that 1 ) the associations between social competence and MVPA engagement were relatively weak over time and 2) the 12-month intervention was effective in increasing children's social competence and MVPA engagement.

The present study considered direct relationships between SDT-based social 
competence and MVPA using a longitudinal study design, when past studies have not directly measured social competence or associations between social competence and physical activity. However, in line with previous studies (Bailey, 2006; Su et al., 2017), the higher social competence skills were linked with higher MVPA participation. The stronger relation was found at the follow-up measurement, although the established relationships were relatively weak across the intervention. It was unexpected that the social competence related with MVPA only on the individual but not on the group level. The reason behind this may be that the perceptions of social competence are strongly based on the individual experiences (Junttila et al., 2006). Even though school-aged children spend a lot of time at school and have a plenty of opportunities to socialize with other students (Su et al., 2017), they are in a developmental stage that is critical to individual psychosocial development (Junttila et al., 2006). In addition, there is strong existing evidence that peer support and participation in community sports are strong predictors of MVPA engagement in school-aged children (Barkley et al., 2014; Sterdt, Liersch, \& Walter, 2013). In other words, children are more likely to choose friends who have similar interests or alter their physical activity behavior in response to their friends instead of perceptions of social competence (Salvy, de la Haye, Bowker, \& Hermans, 2012). Finally, it may be that the significant associations between social competence skills and overall MVPA did not materialize in a longitudinal setting, as both social competence and MVPA scores were relatively high already in the beginning of the data collection. Finnish teachers are well instructed in teaching strategies to promote cooperation and social interaction within children regardless of whether they have low or high social competence skills. To support positive development of social competence and higher MVPA levels in school PE, children could be provided a well-structured environment that gives clear guidelines on tasks (i.e. supportive teacher-student relationships) and opportunities for social learning (i.e. peer relationships), provides optimal challenges, and offers detailed feedback on how to achieve desired outcomes (Taylor \& Ntoumanis, 2007).

Another unexpected finding was also that boys were more physically active than girls only at the baseline measure were. Although this was in line with previous research (Tremblay et al., 2016), it was unclear why the difference did not appear in the follow-up measure. It is possible that the intervention reduced the disparities between some intervention girls and boys, and thus, the difference did not arise at the whole sample level. Few past school-based studies have indicated similar results (Gråstén \& Yli-Piipari, 2019). It may also be that the present MVPA data was collected in a typical, middle-size city in Finland, where local community and school facilities including public sport arenas, indoor gyms, fields, parks, natural trails, and pathways may promote both girls and boys to be physically active in the same way (Sallis et al., 2006).

The results showed that the overall scores of social competence and MVPA levels remained stable in both intervention and control schools. Despite, CPE teaching strategies indicated to be effective over longer time but not when im- 
plemented as a short-term intervention. This was an important finding, especially when most Finnish PE teachers have been shown to use mostly teacher rather than CPE teaching styles (Jaakkola \& Watt, 2011). These results could challenge traditional principles of teaching in PE. In fact, it is confusing that learning physical skills are expected to lead to healthier lifestyle outside the PE classes, while overall MVPA engagement in children and youth is globally decreasing (Tremblay et al., 2016). From this point of view, the current results were promising, especially when the review of Metcalf et al. (2012) provided strong evidence that physical activity interventions have had only a small effect on children's overall activity levels. In fact, they concluded that the longer duration was positively associated with greater reductions in sedentary time but not total MVPA, when those studies reviewed ranged from 4 weeks to 140 weeks. In the review of Dobbins, Husson, DeCorby and LaRocca (2013), a typical duration of school-based program was between 12 weeks to one academic year ( 9 months), whereas the current (long-term) program was implemented over 52 weeks. This may explain, at least in part, why this intervention seemed to be successful in increasing social competence and MVPA participation among fourth- and fifth-grade children in the intervention group. Therefore, some positive impacts of CPE-based activities showed that it was valuable to test the CPE approach in school PE.

This was the first intervention to examine CPE-based strategies in Finnish school PE. Although the impacts were relatively small, the effectiveness of school-based physical activity interventions could also be seen more widely than only increased MVPA levels (Gråstén \& Yli-Piipari, 2019). The present program can have some "hidden" positive impacts (e.g. skills to give constructive feedback), which were not measured, and perhaps, can been seen after years of the intervention. For instance, a recent Finnish school-based program focusing on student-centered methods to increase MVPA during school days indicated that violence and bullying among children reduced during the program, although the MVPA levels did not change over time (Gråstén \& Yli-Piipari, 2019). Because of the nature of the current intervention, it is difficult to draw clear conclusions, which activity was the most effective. As social competence includes several dimensions, it was well justified that the intervention comprised multiple strategies such as workbooks, homework, and lesson time activities. Comprehensive interventions that combine physical activities and motivational adjustments have a greater likelihood of being sustained (Novella, Santos, \& Brichta, 2016), if children in the school take ownership of the activities during the program (Osganian, Parcel, \& Stone, 2003). To conclude, since positive impacts were revealed only after the longer intervention, it seems that applying new strategies into "real" school settings may take time. This means that educators and teachers must be patient, although positive changes may be slow or invisible.

This study was an authentic school PE program trying to increase children's MVPA levels without additional PE time in elementary school children. A key strength of the study was that the data were collected through two time points 
including both psychological and physical activity variables. Despite, this study was not free of limitations. First, the present study used self-reports of social competence and MVPA, which may be inaccurate compared to objective measures in school-aged children and youth (Gråstén \& Watt, 2016). Second, the school-based interventions are always "real life" programs, meaning that all possible factors behind physical activity behavior cannot be controlled. In the current study, neither schools nor children were randomized, because schools voluntarily participated in the study as an intervention or control school. Additionally, the intervention was implemented between research group and PE teachers, which is often the reality with school-based programs.

Future studies could assess the teaching practices using several methods to standardize the practices as accurately as possible. It would be highly beneficial that schools and research institutions would collaborate more effectively to complete these assessments without compromising in teaching practices. As this study focused on elementary school children, CPE-based teaching strategies could be studied among larger samples of children and youth at different ages. It could be informative to use segmented objective measurements to understand the intervention effects on in-school and out-of-school physical activity behavior. The randomized study designs could also provide valuable insights into teacher versus $\mathrm{CPE}$ teaching strategies in school PE.

\section{Conclusion}

The central assumption of the present intervention was that children's social competence and overall MVPA could be enhanced by using CPE methods in school PE. The key findings were that 1) the associations between social competence and MVPA engagement were relatively weak and 2) the 12-month intervention was effective in increasing fourth- and fifth- grade students' social competence and MVPA engagement. Because the positive intervention effects materialized only after the longer intervention, it seems that applying new strategies into actual school settings may take time. Children need to be given sufficient timeframe and opportunities to take ownership of the activities introduced. This requires that researchers and teachers are patient, although positive changes may be slow or invisible.

Following previous research in the field, it is worth to note that all efforts to promote physical activity in children and youth are valuable. Because current school education systems do not have enough curriculum space to substantially increase time for PE, it is important to introduce cost-effective strategies in enhancing children's overall physical activity. Furthermore, traditional teacher-centered practices have shown to lead disparities upon children's physical activity behavior, as overall physical activity levels of school-aged children are decreasing all over the world. Thus, an increasing body of student-centered strategies could be introduced in the PE context. For instance, the CPE-based activities presented could help in increasing children's overall MVPA engagement 
without additional costs by providing positive group learning experiences in PE. Enhancing the capability of teachers through teacher training programs is vital to raising the awareness of CPE pedagogies and lifting student outcomes.

\section{Funding}

This work was supported by the Otto A. Malm Foundation, Finland.

\section{Conflicts of Interest}

The authors declare no conflicts of interest regarding the publication of this paper.

\section{References}

Bailey, R. (2006). Physical Education and Sport in Schools: A Review of Benefits and Outcomes. Journal of School Health, 76, 397-401. https://doi.org/10.1111/j.1746-1561.2006.00132.x

Barkley, J., Salvy, S., Sanders, G., Dey, S., Von Carlowitz, K., \&Williamsson, M. (2014). Peer Influence and Physical Activity Behavior in Young Children: An Experimental Study. Journal of Physical Activity and Health, 11, 404-409. https://doi.org/10.1123/jpah.2011-0376

Berndt, T. (2002). Friendship Quality and Social Development. Current Directions in Psychological Science, 11, 7-10. https://doi.org/10.1111/1467-8721.00157

Currie, C., Zanotti, C., Morgan, A., Currie, D., de Looze, M., Roberts, C., Barnekow, V. et al. (2012). Social Determinants of Health and Well-Being among Young People. Health Behaviour in School-Aged Children (HBSC) Study: International Report from the 2009/2010 Survey. Copenhagen: World Health Organization.

Deci, E., \& Ryan, R. (2000). The "What" and "Why" of Goal Pursuits: Human Needs and the Self-Determination of Behavior. Psychological Inquiry, 11, 227-268. https://doi.org/10.1207/S15327965PLI1104_01

Deci, E., \& Ryan, R. (2008). Facilitating Optimal Motivation and Psychological Well-Being across Life's Domains. Canadian Psychology, 49, 14-23. https://doi.org/10.1037/0708-5591.49.1.14

Dobbins, M., Husson, H., DeCorby, K., \& LaRocca, R. (2013). School-Based Physical Activity Programs for Promoting Physical Activity and Fitness in Children and Adolescents Aged 6 to 18. Cochrane Database of Systematic Reviews, No. 2, CD007651. https://doi.org/10.1002/14651858.CD007651.pub2

Ferrer-Caja, E., \&Weiss, M. (2000). Predictors of Intrinsic Motivation among Adolescent Students in Physical Education. Research Quarterly for Exercise and Sport, 71, 267-279. https://doi.org/10.1080/02701367.2000.10608907

Finnish National Board of Education (2004). National Core Curriculum for Basic Education 2004. Vammala: Vammalan Kirjapaino Oy.

Gråstén, A., \& Watt, A. (2016). A Comparison of Self-Report Scales and Accelerometer-Determined Moderate to Vigorous Physical Activity Scores of Finnish School Students. Measurement in Physical Education and Exercise Science, 20, 220-229. https://doi.org/10.1080/1091367X.2016.1217412

Gråstén, A., \& Yli-Piipari, S. (2019). The Patterns of Children's Moderate to Vigorous Physical Activity and Physical Education Enjoyment through Two Years of School-Based Program. Journal of School Health, 89, 88-98. https://doi.org/10.1111/josh.12717 
Hellison, D. (2010). Teaching Personal and Social Responsibility through Physical Activity. Champaign, IL: Human Kinetics.

Jaakkola, T., \& Watt, A. (2011). Finnish Physical Education Teachers' Self-Reported Use and Perceptions of Mosston and Ashworth's Teaching Styles. Journal of Teaching in Physical Education, 30, 248-262. https://doi.org/10.1123/jtpe.30.3.248

Junttila, N., Voeten, M., Kaukiainen, A., \& Vauras, M. (2006). Multisource Assessment of Children's Social Competence. Educational and Psychological Measurement, 66, 874-895. https://doi.org/10.1177/0013164405285546

Kirk, D. (2013). Educational Value and Models Based Practice in Physical Education. Educational Philosophy and Theory, 45, 973-986. https://doi.org/10.1080/00131857.2013.785352

Kokkonen, J., Yli-Piipari, S., Kokkonen, M., \& Quay, J. (2018). Effectiveness of a Creative Physical Education Intervention on Elementary School Students' Leisure-Time Physical Activity Motivation and Overall Physical Activity in Finland. European Physical Education Review. https://doi.org/10.1177/1356336X18775009

Kulinna, P. (2008). Models for Curriculum and Pedagogy in Elementary School Physical Education. Elementary School Journal, 108, 219-227. https://doi.org/10.1086/529104

Kwon, K., Kim, E., \& Sheridan, S. (2014). The Role of Beliefs about the Importance of Social Skills in Elementary Children's Social Behaviors and School Attitudes. Child Youth Care Forum, 43, 455-467. https://doi.org/10.1007/s10566-014-9247-0

Little, R., \& Rubin, D. (2002). Statistical Analysis with Missing Data. New York: Wiley. https://doi.org/10.1002/9781119013563

McKenzie, T. (2007). The Preparation of Physical Educators: A Public Health Perspective. Quest, 59, 345-357. https://doi.org/10.1080/00336297.2007.10483557

Metcalf, B., Henley, W., \& Wilkin, T. (2012). Effectiveness of Intervention on Physical Activity of Children: Systematic Review and Meta-Analysis of Controlled Trials with Objectively Measured Outcomes. British Medical Journal, 345, e5888. https://doi.org/10.1136/bmj.e5888

Merrell, K., Felver-Gant, J., \& Tom, K. (2011). Development and Validation of a Parent Report Measure for Assessing Social-Emotional Competencies of Children and Adolescents. Journal of Child and Family Studies, 20, 529-540. https://doi.org/10.1007/s10826-010-9425-0

Muthén, B., \& Asparouhov, T. (2003). Modeling Interactions between Latent and Observed Continuous Variables Using Maximum-Likelihood Estimation in Mplus. https://www.semanticscholar.org/paper/Modeling-Interactions-Between-Latent-and-O bserved-Muth\%C3\%A9n-Asparouhov/978b5efe1c1d7973a618fc6ccc1798ced383a9c9

Muthén, L., \& Muthén, B. (2013). Mplus User’s Guide. Los Angeles, CA: Muthén \& Muthén.

Novella, M., Santos, J., \& Brichta, J. (2016). Moving Ahead: School-Based Interventions to Reduce Physical Inactivity and Sedentary Behaviour. Ottawa: The Conference Board of Canada.

Ntoumanis, N., \& Standage, M. (2009). Motivation in Physical Education Classes: A Self-Determination Theory Perspective. Theory and Research in Education, 7, 194-202. https://doi.org/10.1177/1477878509104324

Osganian, S., Parcel, G., \& Stone, E. (2003). Institutionalization of a School Health Promotion Program: Background and Rationale of the CATCH-ON Study. Health Education and Behavior, 30, 410-417. https://doi.org/10.1177/1090198103252766

Quay, J. (2015). Understanding Life in School: From Academic Classroom to Outdoor 
Education. New York: Palgrave Macmillan. https://doi.org/10.1057/9781137391230

Quay, J., Kokkonen, J., \& Kokkonen, M. (2016). Finnish Interpretations of Creative Physical Education. Asia-Pacific Journal of Health, Sport and Physical Education, 7, 173-190. https://doi.org/10.1080/18377122.2016.1196115

Quay, J., \& Peters, J. (2012). Creative Physical Education: Integrating Curriculum through Innovative PE Projects. Champaign, IL: Human Kinetics.

Rubin, K., \& Rose-Krasnor, L. (1992). Interpersonal Problem Solving. In V. Van Hassett, \& M. Hersen (Eds.), Handbook of Social Development (pp. 283-323). New York: Plenum. https://doi.org/10.1007/978-1-4899-0694-6_12

Sallis, J., Cervero, R., Ascher, W., Henderson, K., Kraft, M., \& Kerr, J. (2006). An Ecological Approach to Creating Active Living Communities. Annual Review of Public Health, 27, 297-322. https://doi.org/10.1146/annurev.publhealth.27.021405.102100

Salvy, S., de la Haye, K., Bowker, J., \& Hermans, R. (2012). Influence of Peers and Friends on Children's and Adolescents' Eating and Activity Behaviors. Physiology and Behavior, 106, 369-378. https://doi.org/10.1016/j.physbeh.2012.03.022

Slingerland, M. (2014). Physical Education's Contribution to Levels of Physical Activity in Children and Adolescents. Doctoral Dissertation, Maastricht: Maastricht University.

Snijders, T., \& Bosker, R. (2012). Multilevel Analysis: An Introduction to Basic and Advanced Multilevel Modeling. London: Sage Publishers.

Standage, M., Duda, J., \& Ntoumanis, N. (2003). Predicting Motivational Regulations in Physical Education: The Interplay between Dispositional Goal Orientations, Motivational Climate and Perceived Competence. Journalof Sports Sciences, 21, 631-647. https://doi.org/10.1080/0264041031000101962

Sterdt, E., Liersch, S., \& Walter, U. (2013). Correlates of Physical Activity of Children and Adolescents: A Systematic Review of Reviews. Health Education Journal, 73, 72-89. https://doi.org/10.1177/0017896912469578

Su, J., Wu, Z., \& Su, Y. (2017). Physical Exercise Predicts Social Competence and General Well-Being in Chinese Children 10 to 15 Years Old: A Preliminary Study. Child Indicator Research, 6, 1-15. https://doi.org/10.1007/s12187-017-9523-2

Taylor, I., \& Ntoumanis, N. (2007). Teacher Motivational Strategies and Student Self-Determination in Physical Education. Journal of Educational Psychology, 99, 747-760. https://doi.org/10.1037/0022-0663.99.4.747

Taylor, I., Ntoumanis, N., Standage, M., \& Spray, C. (2010). Motivational Predictors of Physical Education Students' Effort, Exercise Intentions, and Leisure-Time Physical Activity: A Multilevel Linear Growth Analysis. Journal of Sport and Exercise Psychology, 32, 99-120. https://doi.org/10.1123/jsep.32.1.99

Tremblay, M., Barnes, J., González, S., Katzmarzyk, P., Onywera, V., Reilly, J., \& Tomkinson, G. (2016). Global Matrix 2.0: Report Card Grades on the Physical Activity of Children and Youth Comparing 38 Countries. Journal of Physical Activity and Health, 13, 343-366. https://doi.org/10.1123/jpah.2016-0594

van Sluijs, E., McMinn, A., \& Griffin, S. (2007). Effectiveness of Interventions to Promote Physical Activity in Children and Adolescents: Systematic Review of Controlled Trials. British Medical Journal, 335, 703. https://doi.org/10.1136/bmj.39320.843947.BE

Weiss, M. (2000). Motivating Kids in Physical Activity. Research Digest President's Council on Physical Fitness and Sports, 3, 1-8. https://doi.org/10.1037/e603522007-001

World Health Organization (2018). Physical Activity.

http://www.who.int/topics/physical_activity/en 